\title{
Assessing Tensile Bond Strength Between Denture Teeth and Nano-Zirconia Impregnated PMMA Denture Base
}

This article was published in the following Dove Press journal: International Journal of Nanomedicine

\author{
Saleh Zidan ${ }^{1,2}$ \\ Nikolaos Silikas (D) \\ Julfikar Haider $\mathbb{D}^{3}$ \\ Abdulaziz Alhotan (D) \\ Javad Jahantigh (D) \\ Julian Yates $\mathbb{D}^{\prime}$ \\ 'Dentistry, School of Medical Sciences, \\ University of Manchester, Manchester \\ MI3 9PL, UK; ${ }^{2}$ Department of Dental \\ Materials, Faculty of Dentistry, Sebha \\ University, Sebha, Libya; ${ }^{3}$ Department of \\ Engineering, Manchester Metropolitan \\ University, Manchester MI 5GD, UK
}

Correspondence: Saleh Zidan Dentistry, School of Medical Sciences, University of Manchester, Coupland Building 3, Oxford Road, Manchester MI3 9PL, UK

Tel +44-7933096536

Email saleh_0072002@yahoo.co.uk
Purpose: This study evaluated tensile bond strength (TBS) between anterior acrylic teeth and denture bases made of high-impact heat-cured acrylic resin (HI PMMA) impregnated with zirconia nanoparticles.

Materials and Methods: A total of 30 specimens (each specimen containing a set of six upper anterior teeth) were fabricated from HI PMMA denture base acrylic resin reinforced with different weight concentrations of zirconia nanoparticles: $0 \%$ (control), $1.5 \%, 3 \%, 5 \%$, $7 \%$ and $10 \%$. TBS was tested according to a British standard (BS EN ISO 22112: 2017). A one-way analysis of variance (ANOVA) was employed with a Tukey post-hoc test.

Results: TBS values between the anterior teeth (central and lateral incisors and canine) and HI-PMMA denture base groups containing 7 wt. $\%(261.5 \pm 66.0 \mathrm{~N}, 172.5 \pm 57.4 \mathrm{~N}$ and $271.9 \pm 86.3 \mathrm{~N})$ and $10 \mathrm{wt} . \%(332.1 \pm 122.9 \mathrm{~N}, 165.4 \pm 48.7 \mathrm{~N}$ and $301.6 \pm 73.2 \mathrm{~N})$ zirconia were significantly lower compared to the control group $(645.4 \pm 84.8 \mathrm{~N}, 306.1 \pm 81.6 \mathrm{~N}$ and $496.7 \pm 179.1 \mathrm{~N})$ and the other nanocomposite groups. However, TBS values for HI PMMA with 1.5 wt.\% $(534.4 \pm 115.3 \mathrm{~N}, 304.7 \pm 86.4 \mathrm{~N}, 514.0 \pm 143.2 \mathrm{~N}), 3$ wt.\% $(685.7 \pm 159.6 \mathrm{~N}$, $281.1 \pm 78.3 \mathrm{~N}, 462.6 \pm 122.1 \mathrm{~N})$ and 5 wt. $\%(514.5 \pm 134.3 \mathrm{~N}, 229.8 \pm 67.3 \mathrm{~N}, 387.2 \pm 99.4$ $\mathrm{N})$ zirconia showed slightly lower values than that of the control group but these were not significant. Failure modes between the teeth and denture base nanocomposites were predominantly cohesive fractures, which were clinically acceptable according to the Standard.

Conclusion: The addition of zirconia nanoparticles to HI PMMA denture base at high concentration ( 7 wt.\% and 10 wt. \%) significantly $(p<0.05)$ reduced the bonding strength for all types of anterior teeth compared to the control group.

Keywords: denture, PMMA, zirconia; $\mathrm{ZrO}_{2}$, nanocomposite, tensile bond strength; TBS, failure mode

\section{Introduction}

Acrylic resin teeth have been widely used in the fabrication of partial and complete removable dentures and more recently in implant-supported prostheses. ${ }^{1}$ These prostheses, especially implant-retained overdentures help prevent bone loss and provide more stability and retention during functioning. They have also been shown to improve patient's quality of life when compared to the conventional dentures. ${ }^{2}$ When processing acrylic teeth into an acrylic resin denture base such as poly-methyl methacrylate (PMMA), a strong bond is formed with the denture base through copolymerization with a cross-bonding element due to their chemical compatibility. ${ }^{3,4}$ Compared to other materials used 
to produce prostheses, other advantages of acrylic teeth are ease of adjustment, low cost. ${ }^{2,3,5}$

The adhesion between acrylic teeth and denture base resin is one of the most important factors for desirable performance and durability of a denture. ${ }^{6,7}$ However, tooth debonding or fracture remains a major problem in clinical applications. ${ }^{8}$ It has been reported that the failure of dentures due to tooth debonding usually occurs in the anterior region of the denture and ranges between $22 \%$ and $30 \% .^{2,7-12}$ More recently, the use of implant-supported prostheses and over-dentures has demonstrated improved masticatory function, and this has led to higher biting forces on the teeth. This further increases the likelihood of tooth debonding from the denture base. ${ }^{2,13}$ A number of factors could affect adhesion of the teeth to the denture base, such as poor chemical incompatibility between different types of tooth and denture base materials or a smaller ridge lap surface area on the tooth available for bonding. ${ }^{7-9,12}$ Other factors include excessive occlusal force or fatigue loading on the teeth during mastication, surface contamination due to residual wax left at the interface between tooth and base material during denture fabrication, inappropriate use of separating medium during acrylic resin processing, insufficient monomer availability during polymerization and ineffective or sub-optimal curing methods. ${ }^{5,8,9,14}$ Evidence has also been presented that regular use of cleansing and disinfection chemicals could cause a change in the mechanical and physical properties of the denture base and tooth materials leading to bond weakening and subsequent failure. ${ }^{15}$ These factors can cause tooth failure either adhesively or cohesively, or a combination of both. ${ }^{3}$ Adhesive failure occurs along the junction of contact between the acrylic tooth and denture base and is characterized by the absence of tooth or denture base fragments on the opposing surface. When the fracture occurs completely within the denture tooth or denture base acrylic resin, it is called a cohesive failure. However, if there are any fragment of denture base material on the tooth surface or any part of the tooth material on the denture base, it is called mixed mode of failure. ${ }^{3}$

Previous studies have investigated different methods to enhance this bond strength, and these have included mechanical and chemical preparation of the ridge-lap surface of the tooth. ${ }^{10,13}$ The mechanical preparations reported are pins, diatoric undercuts, grooving, grinding of the glossy surface and high-energy abrasion of teeth ${ }^{1,11,16}$ to improve mechanical interlocking during processing. A number of review studies also reported that mechanical modification of the ridge-lap surfaces of the acrylic teeth and demonstrated an increase in bond strength, ${ }^{8,11,16,17}$ although other studies did not find any improvement. ${ }^{8,11,13}$ Similarly, chemical modification employing either monomers (MMA), solvents or adhesive bonding agents applied to the contact surfaces ${ }^{11,14}$ in order to increase the chemical bonding has also been investigated. Several investigators documented enhancements in bond strength with chemical surface treatments, but others found no significant improvements. ${ }^{8,10,11,18}$ Perea et al ${ }^{11}$ evaluated the effect of various chemical surfaceconditioning monomers on ridge-lap surfaces of acrylic denture teeth, and the results demonstrated an improvement in the shear bond strength as the monomer systems caused dissolution of denture teeth. Laser surface treatment was also applied to improve the bond strength though limited success was achieved over the chemical ${ }^{19}$ or mechanical techniques. ${ }^{20}$

In addition to surface modifications, denture base materials and their polymerization technique can have a measurable influence on the bond strength. Increased bond strength was obtained with conventional heat-polymerized acrylic resin when compared to microwave-polymerized acrylic resin. ${ }^{21}$ In another investigation, light- and microwave-cured resins showed reduced bond strength in comparison to the conventional heat-cured acrylic resins. ${ }^{6}$ However, in contrast, a more recent study found that microwave-assisted polymerization of denture base resins could improve the bond strength when compared to standard techniques. ${ }^{22}$ Cardash et al reported that high-impact heat-cured denture base acrylic resin increased bond strength more than the conventional resin without any impact modifier. ${ }^{23}$ However, further research is needed to evaluate the bond strength of highimpact heat-cured PMMA resin to denture teeth.

A number of national and international standards are available to determine bond strength, but there exists a wide variation in the materials used, shape, size and fabrication techniques of test samples and the methodology employed for testing. ${ }^{8}$ In clinical conditions, the direction of load applied to the denture teeth during mastication can lead to separation of teeth by a combination of tensile, compressive and shear failure. ${ }^{6}$ Various methods have been used to estimate the adhesion bond strength between the teeth and denture base, and include tensile or (micro) tensile, shear, compression, flexural strength tests and finite element stress analysis. ${ }^{2,6}$

Zirconia nanoparticles have been investigated in denture base acrylic resin to help improve its mechanical strength 
and to avoid premature fatigue or fracture failures. ${ }^{24}$ According to a previous study it was determined that denture base nanocomposites developed with 3-5 wt.\% of zirconia PMMA matrix can result in improved mechanical properties. $^{25}$ However, it is acknowledged that improvements in the mechanical properties of denture bases alone cannot fully prevent denture failures in clinical practice. A combination of high strength in the denture base, and a strong bond between the teeth and base is vital to ensure sound performance and durability of the prosthesis. Therefore, it is essential to evaluate the bond strength of emerging denture base materials such as zirconia-PMMA nanocomposite. At present, no studies are available in the literature relating to the evaluation of tensile bond strength (TBS) between acrylic teeth and denture base materials composed of zirconia-based PMMA nanocomposites.

Hence, the aim of this study was to investigate the influence of adding different $\mathrm{ZrO}_{2}$-nanoparticles concentrations $(0 \%, 1.5 \%, 3 \%, 5 \%, 7 \%$, and 10 wt. $\%)$ to HI-PMMA, on the TBS between acrylic denture teeth and denture base. The first null hypothesis was based on the assumption that there would be no significant difference in the TBS of denture bases made of zirconia impregnated PMMA nanocomposites and pure acrylic denture teeth. The second null hypothesis assumed that the British standard provided clear guidance on TBS sample preparation and jig design for displacing teeth.

\section{Materials and Experimental Method Denture Base and Tooth Materials}

A commercially available, denture base resin and Yttriastabilized zirconia $\left(\mathrm{ZrO}_{2}\right)$ nanoparticles were used for fabricating the nanocomposite denture base specimens. ${ }^{25}$ The specifications for the other materials including the artificial teeth (cross-linked polymethylmethacrylate with colour pigments) used in preparing the denture specimens for bond strength tests are presented in Table 1 .

\section{Surface Treatment of Zirconia Nanoparticles and Grouping}

Zirconia nanoparticle surface was treated with 7 wt.\% silane coupling agent (3-trimethoxysilyl propyl methacrylate; product no. 440,159, Lot number. 2530-85-0, Sigma Aldrich) to avoid aggregation of the mixture as explained in author's previous publication. ${ }^{25}$ Based on a pilot study, relevant studies in literature and previous investigations $^{25}$ by the authors a decision was made to utilize the different weight percentages of silanized
Table I Materials Used in This Study for TBS Sample Preparation

\begin{tabular}{|c|c|c|c|}
\hline Materials & $\begin{array}{l}\text { Trade } \\
\text { Name }\end{array}$ & Manufacturer & $\begin{array}{l}\text { Lot. } \\
\text { Number }\end{array}$ \\
\hline $\begin{array}{l}\text { High-impact } \\
\text { heat-cured } \\
\text { acrylic denture } \\
\text { base resin }\end{array}$ & $\begin{array}{l}\text { HI } \\
\text { Metrocryl }\end{array}$ & $\begin{array}{l}\text { Metrodent } \\
\text { Limited, } \\
\text { Huddersfield, } \\
\text { UK }\end{array}$ & $\begin{array}{l}\text { Powder } \\
(22828) \\
\text { Liquide (103/ } \\
4)\end{array}$ \\
\hline $\begin{array}{l}\text { Yttria-stabilized } \\
\text { zirconium oxide } \\
\text { or zirconia }\end{array}$ & $\begin{array}{l}\text { Zirconium } \\
\text { oxide }\end{array}$ & $\begin{array}{l}\text { Sky Spring Nano } \\
\text { Materials, Inc, } \\
\text { Houston, TX, } \\
\text { USA }\end{array}$ & $8522-120315$ \\
\hline $\begin{array}{l}\text { Acrylic resin } \\
\text { teeth }\end{array}$ & $\begin{array}{l}\text { Artic } 6 \mathrm{M} \\
\text { S40 shade } \\
\text { A2 }\end{array}$ & $\begin{array}{l}\text { Metrodent } \\
\text { Limited, } \\
\text { Huddersfield, } \\
\text { UK }\end{array}$ & 1813342008 \\
\hline Dental Plaster & $\begin{array}{l}\text { Flasking } \\
\text { plaster }\end{array}$ & $\begin{array}{l}\text { Saint-Gobain, } \\
\text { Formula, } \\
\text { Newark, UK }\end{array}$ & $04 \mid 1217-3$ \\
\hline Type 4 Diestone & Metrostone & $\begin{array}{l}\text { Metrodent } \\
\text { Limited, } \\
\text { Huddersfield, } \\
\text { UK }\end{array}$ & $032218-1$ \\
\hline $\begin{array}{l}\text { Addition cured } \\
\text { 2-part silicone } \\
\text { lab putty I:I }\end{array}$ & $\begin{array}{l}\text { Matrix Duo } \\
\text { Laboratory } \\
\text { Putty }\end{array}$ & $\begin{array}{l}\text { Metrodent } \\
\text { Limited, } \\
\text { Huddersfield, } \\
\text { UK }\end{array}$ & | $8222-70054$ \\
\hline
\end{tabular}

zirconia nanoparticles in the denture base formulation. The composition details of the specimen groups used in this study are described in Table 2, all processed using an acrylic resin powder-to-monomer ratio of $21 \mathrm{~g}: 10 \mathrm{~mL}$, in accordance with the manufacturer's instructions. With increasing weight percentage of zirconia, the bright pink color of PMMA slightly degraded to whitish pink as detailed in the author's previous publication. ${ }^{26}$

\section{Preparation of Denture Teeth}

Thirty specimens each containing six maxillary anterior teeth (each set consisting of two central, lateral and canine teeth) manufactured with acrylic resin were used for the preparation of 30 denture specimens for TBS tests. The glossy layer was removed from the ridge-lap surfaces of the teeth and a groove was made in each using a tungsten carbide bur (D B Orthodontics, West Yorkshire, UK) as shown in Figure 1. Three different teeth with different geometries were selected in this study to analyse their geometrical effects on the bonding strength. 
Table 2 Weight Percent Zirconia in Combination with Acrylic Resin Powder as Well as Monomer Content of the Specimen Groups

\begin{tabular}{|l|l|l|l|l|}
\hline Experimental Groups & Zirconia (wt.\%) & Zirconia (g) & HI PMMA Powder (g) & HI MMA Monomer (mL) \\
\hline GI (Control) & 0.0 & 0.000 & 25.000 & 12.0 \\
G2 & 1.5 & 0.375 & 24.625 & 12.0 \\
G3 & 3.0 & 0.750 & 24.250 & 12.0 \\
G4 & 5.0 & 1.250 & 23.750 & 12.0 \\
G5 & 7.0 & 1.750 & 23.250 & 12.0 \\
G6 & 10.0 & 2.500 & 22.500 & 12.0 \\
\hline
\end{tabular}

The groove dimensions for central incisor and canine teeth were approximately $2.50 \pm 0.10 \mathrm{~mm}$ long and $2.50 \pm$ $0.20 \mathrm{~mm}$ wide, but the lateral tooth dimensions were smaller by approximately $1.0 \mathrm{~mm}$. Mechanical tooth preparation was undertaken as previous studies have reported it may enhance the bond at the interface between teeth and denture acrylic resin, and thus made recommendations for best clinical practice. ${ }^{17}$ After preparation, each tooth was thoroughly cleaned with pressurized air to remove any dust residue on the tooth surfaces that may affect the bonding.

\section{Preparation of Specimens}

Specimens were prepared on base plate wax with a dimension of $75 \mathrm{~mm} \times 55 \mathrm{~mm} \times 7 \mathrm{~mm}$ at room temperature $\left(23^{\circ} \mathrm{C}\right)$. On the upper surface of the wax base, a rectangular groove $5 \mathrm{~mm}$ wide and $1.5 \mathrm{~mm}$ deep was prepared. The six maxillary teeth were then mounted onto the wax groove using heated base plate wax. Excess wax attached with the neck, lingual surfaces or incisal portion of the teeth was carefully removed.

A denture flask (Bracon limited, UK) was filled with dental plaster and Type 4 Diestone and then the specimen was removed from the mould. The prepared wax base with teeth was then placed onto the Diestone within the flask and left to dry for approximately $20 \mathrm{~min}$. Once the dental plaster was set, the wax was flushed away with boiling water in a dewaxing machine (Labormat SD, Dreve Dentamid GmbH, Germany) and the flask cleaned with steam (Cape Watch, UK) to remove any remaining wax in the plaster mould cavity. Nanocomposite denture base resins were prepared by mixing liquid MMA, zirconia nanoparticles and powdered PMMA according to Table 2. When the mixture reached a consistent "dough" like stage (working stage), it was packed into the flask and closed. The flask was then immersed in a temperature-controlled curing water bath for $6 \mathrm{hr}$, to allow polymerization to $95^{\circ} \mathrm{C}$. Once completed, the flask was removed from the curing bath, cooled slowly for 30 min at room temperature and opened to remove the specimen. The specimen was placed in an ultrasonic cleaning machine with water (Elma, Birmingham, UK) to clean the die stone from the specimen. Any remaining die stone was trimmed away using a fine tungsten carbide bur (D B Orthodontics, West Yorkshire, UK), and the
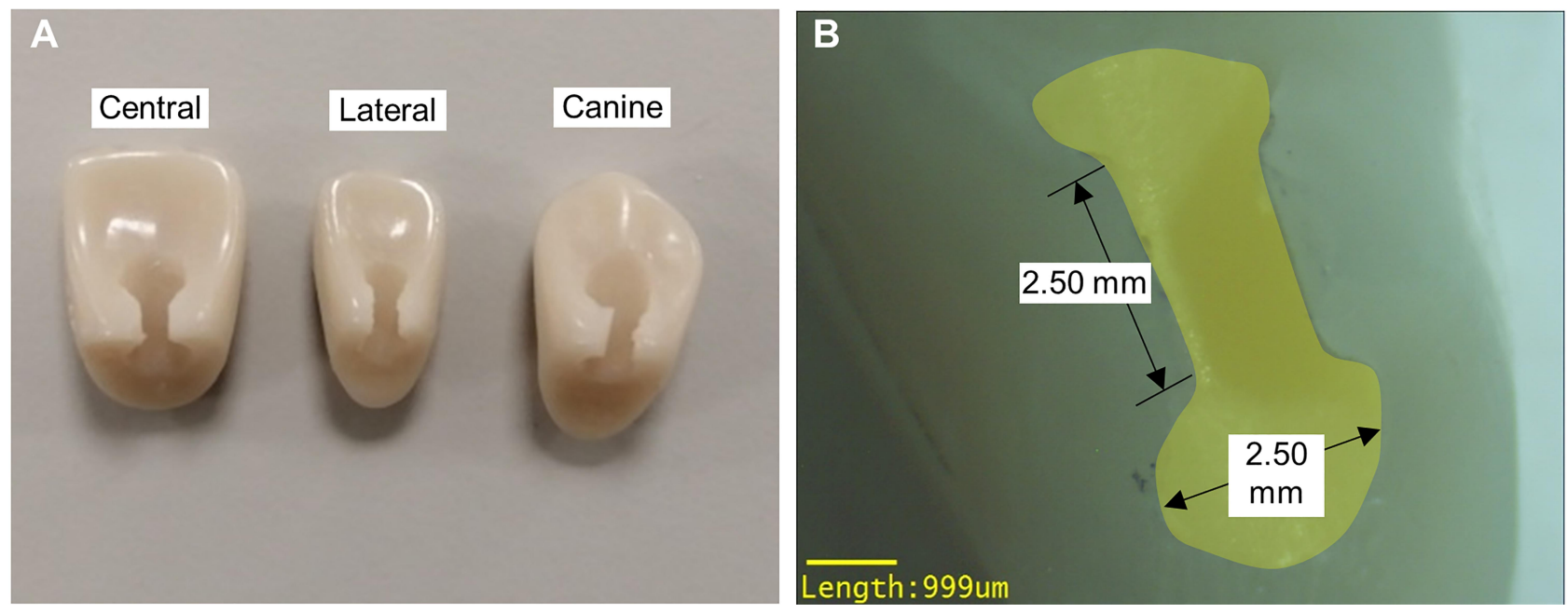

Figure I Photograph of $(\mathbf{A})$ different types of grooved anterior teeth and $(\mathbf{B})$ a sample groove dimensions of a canine tooth. 
specimen finally polished with pumice powder in a polishing machine (Tavom, Wigan, UK).

For consistency, the specimen was duplicated using an addition cured 2-part silicone putty with a 1:1 ratio to produce an exact copy of the wax specimen. Figure 2 presents the duplication steps. The duplicated wax specimens were used to fabricate all thirty specimens following the same procedure detailed. The specimens were stored in distilled water at $37^{\circ} \mathrm{C}$ for 7 days before conducting TBS tests.

\section{Tensile Bond Strength (TBS) Test}

The thirty specimens were prepared for TBS tests using a universal testing machine (Hounsfield Tensometer, H10KS, Germany), according to the British standard (BS EN ISO 22112: 2017). ${ }^{27}$ A schematic diagram of the specimen with the teeth mounted on the nanocomposite denture base with dimensions of $75 \pm 0.03 \mathrm{~mm}$ in length $\times 55 \pm 0.03 \mathrm{~mm}$ in width $\times 7 \pm 0.03 \mathrm{~mm}$ in height is shown in Figure 3 .

The specimens were removed from the distilled water and placed in the same metal grip former, which was fixed at the bottom of the testing machine. A jig was designed to pull individual teeth out from the specimens by fixing it at the upper cross-head of the universal testing machine. The jig was designed in the shape of a tuning fork with two adjustable screws in the two legs as shown in Figure 4.

The screws were adjusted to contact the base from both sides to tighten the specimen. One screw was located underneath the lingual area of a tooth and the other screw under the neck portion of the tooth to allow a direct pull on the ridge lap area in a labial direction during tensile testing. Figure 5 presents image of the experimental set-up when a tooth was pulled up.

TBS test was conducted at a crosshead speed of $5 \mathrm{~mm} / \mathrm{min}$ with a pre-load $0.3 \mathrm{~N}$ and the load cell capacity was $1000 .^{7,23,27}$ The load was applied to individual teeth until failure occurred and the maximum breaking forces were recorded in Newtons. The broken specimens were checked visually and under a microscope to determine whether the failure modes were adhesive, cohesive or a combination of both.

\section{Examination of Fractured Specimens}

The failure modes and mechanisms between the denture base and tooth were analysed visually and using an optical microscope and a scanning electron microscope (SEM) (Carl Zeiss Ltd, 40 VP, Smart SEM). The failed specimens were sectioned to the correct size, mounted onto aluminium stubs using adhesive and coated with a thin layer of Gold/Palladium ( $\mathrm{Au} / \mathrm{Pd})$ using a sputter coater to enhance conductivity. The stubs were then placed into a numbered sample holder and loaded into the SEM for imaging using a secondary electron detector at an acceleration voltage of $2.0 \mathrm{kV}$.

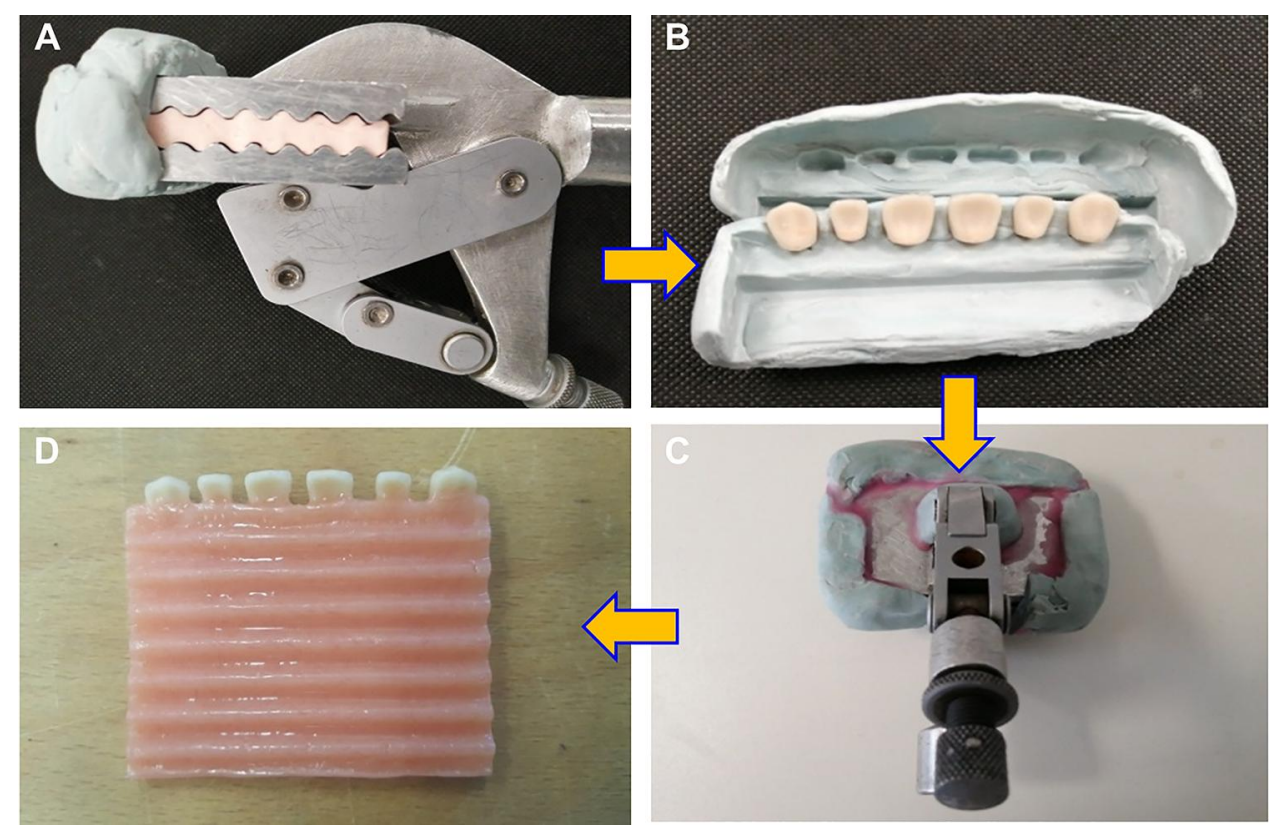

Figure 2 Photographs illustrating the steps of duplication of wax specimen in the grip former by addition cured 2-part silicone putty: (A) creating silicone putty duplication mould, (B) placing maxillary anterior teeth in the duplication mould, (C) placing duplication mould containing teeth in the grip former and pouring denture wax and (D) removing final wax specimen from the silicone putty mould. 


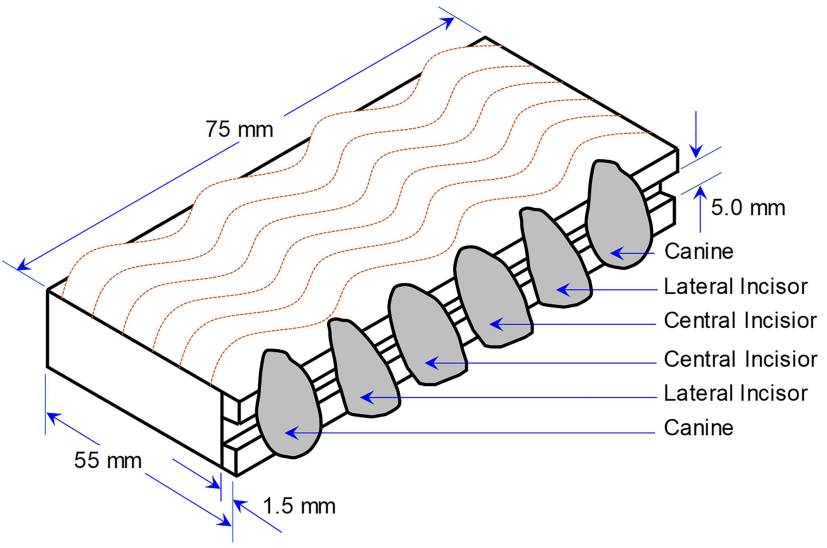

Figure 3 Schematic diagram of prepared specimen with different dimensions (adapted from Kurt et $\mathrm{al}^{7}$ ).

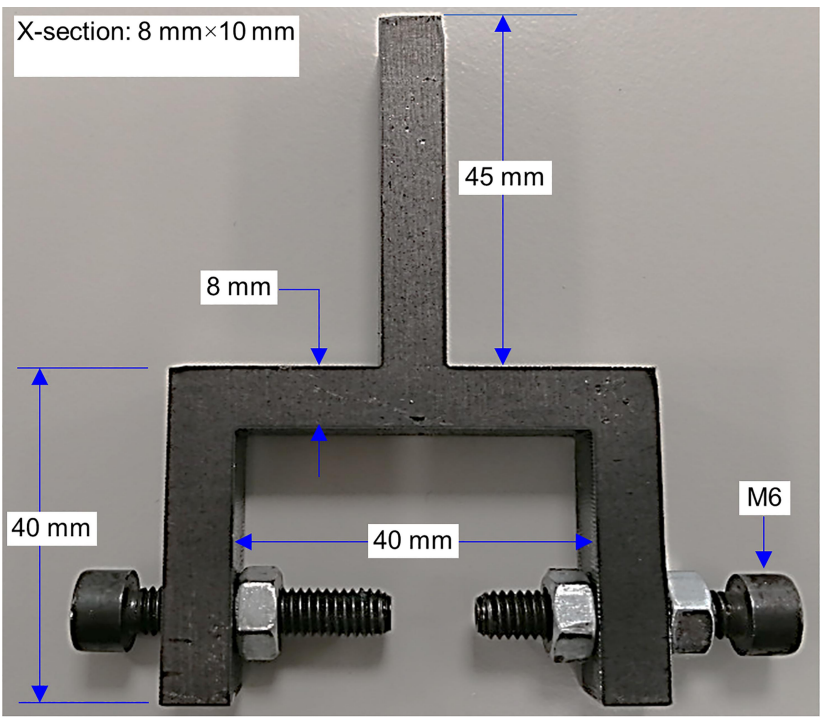

Figure 4 Photograph of the jig used for pulling teeth from the test specimen.

\section{Statistical Analyses}

The TBSs were recorded in terms of breaking forces and statistically analysed using the statistical software (SPSS statistics version 23, IBM, New York, NY, USA). A nonsignificant Shapiro-Wilk test showed that the data for tensile bonding strength was normally distributed and there was homogeneity of variance. A one-way analysis of variance (ANOVA) was then used and means were compared with a Tukey-post-hoc test at 0.05 significant level.

\section{Results}

\section{Tensile Bonding Strength}

Thirty specimens with a total of 180 teeth in six specimen groups were subjected to TBS tests. Typical force vs

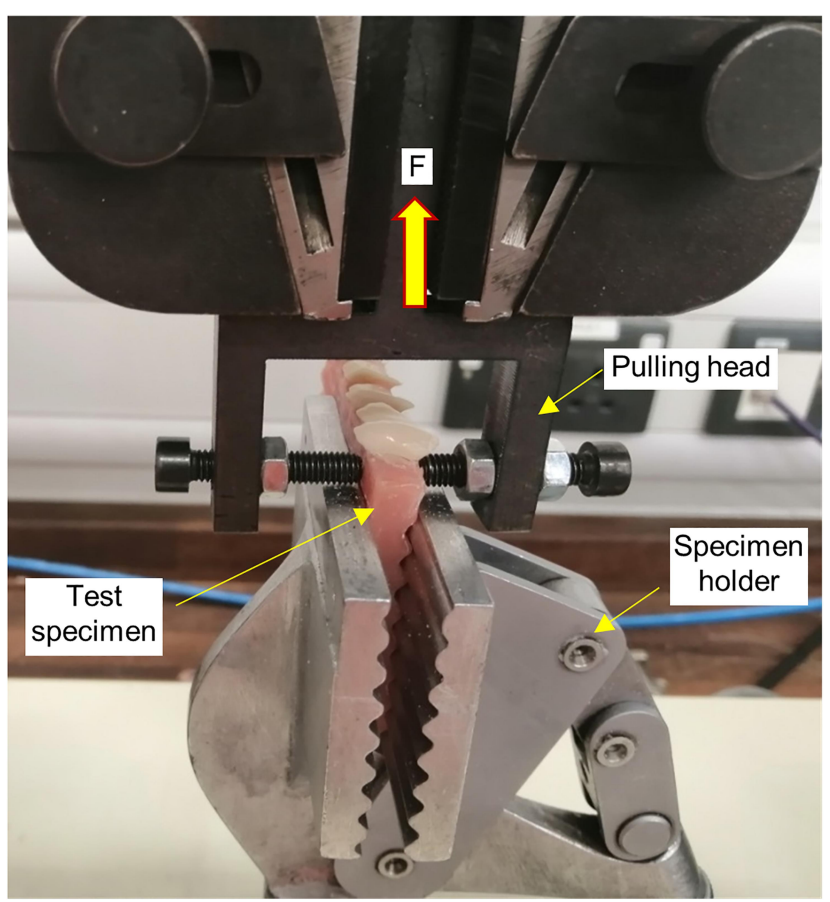

Figure 5 Photograph illustrating the bonding strength test set-up under tensile loading condition using Hounsfield universal testing machine.

elongation graphs for the different denture base materials are presented in Figure 6. The mean TBS values with standard deviations are listed in Table 3 for each type of tooth and presented as a bar chart in Figure 7. The mean TBS values of the groups containing $7 \mathrm{wt} . \%$ and $10 \mathrm{wt} . \%$ of zirconia were significantly lower $(\mathrm{P}<0.05)$ than that of the control group for all three types of teeth: central ( $\mathrm{P}$ values for $7 \mathrm{wt} \%$ and $10 \mathrm{wt} \%$ groups: 0.000 and 0.000 ), lateral (P values for $7 \mathrm{wt} \%$ and $10 \mathrm{wt} \%$ groups: 0.001 and 0.000 ) and canine (P values for $7 \mathrm{wt} \%$ and $10 \mathrm{wt} \%$ groups: 0.000 and 0.002). Furthermore, in general, the groups containing 1.5 wt. $\%, 3$ wt.\% and 5 wt. $\%$ of zirconia showed lower TBS values compared to the control group but statistically these were not significantly lower $(\mathrm{P}>0.05)$. However, TBS between the central incisor teeth and denture base group containing $3 \mathrm{wt} . \%$ zirconia showed the highest mean TBS value $(685.7 \mathrm{~N})$, though the highest TBS values for lateral and canine teeth were recorded with the denture base made of PMMA with no zirconia particles (control group).

Figure 8 presents the number of teeth that fractured through different types of failure modes for each type of tooth. Complete adhesive failure at the interface between the teeth and denture base material was not observed for any tooth within the six specimen groups. The most common failure mode was cohesive failure representing 


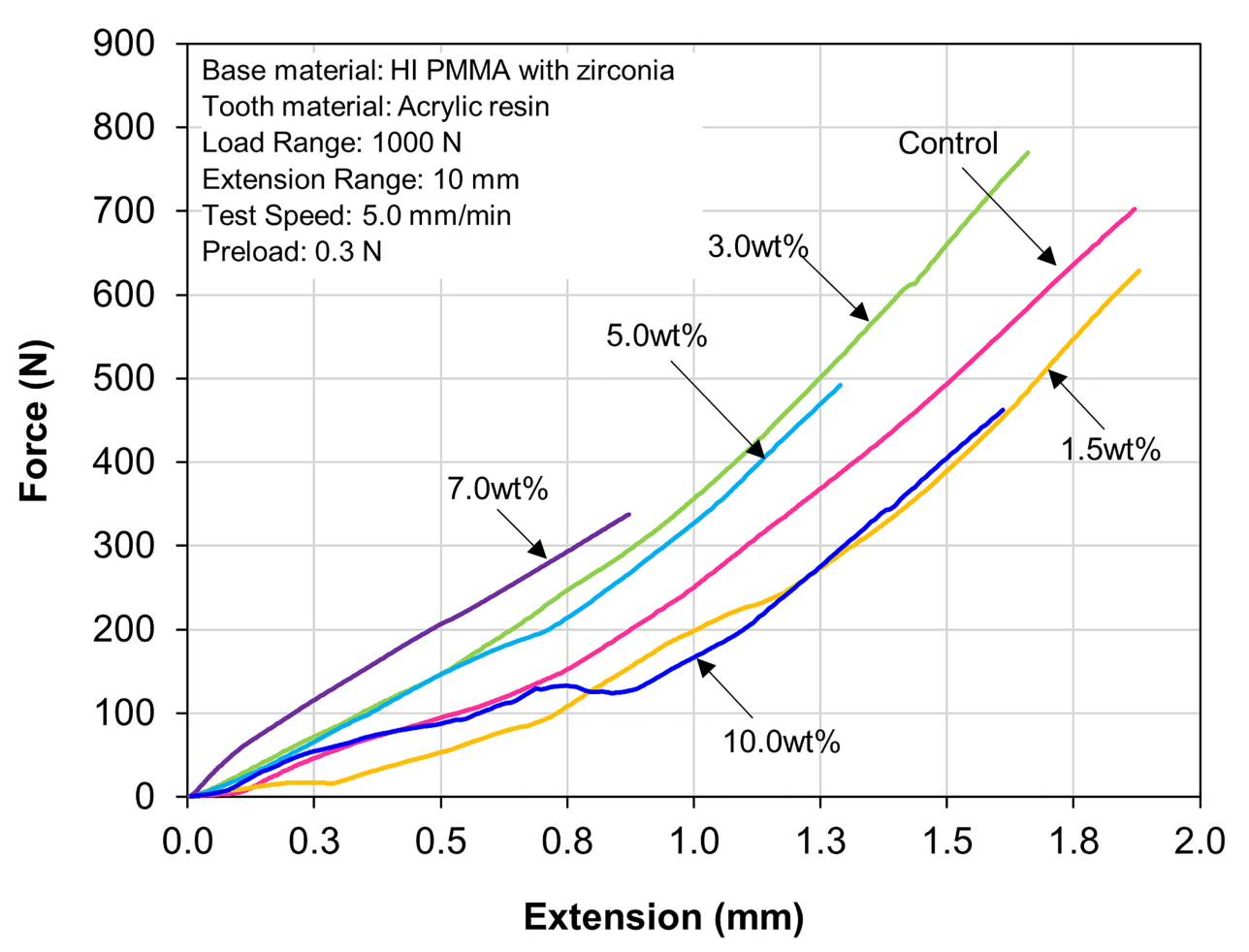

Figure 6 Line graph showing the representative force vs extension graphs for different test groups during TBS tests.

approximately $76 \%$ of the total failures. In general, the majority of the cohesive failures occurred within the teeth. Additionally, a few mixed cases, which combined both cohesive and adhesive failures, were observed and these represented the rest of the failures.

A strong negative correlation $\left(r^{2}=0.84\right)$ was found between the concentration of zirconia and the TBS with canine teeth as shown in Figure 9.

\section{Fractured Sample Analysis}

In some cases, the failure propagated through the root of the groove at the ridge lap area and fractured parts of the tooth from two sides of the groove remained in the denture base as shown in Figure 10.
Micrographs of fractured surfaces presented in Figure 11A illustrated a mixed cohesive and adhesive failure, where part of the denture base PMMA resin remained on the tooth. In general, at low magnification, it appeared that both materials were strongly bonded. At higher magnification, a strong bond was further evidenced with no gap at the material interface at one part, but a small interfacial gap was observed indicating a possible weaker bond. A strong bond was also evidenced by a layer of base material attached on the tooth in Figure 11B. Figure 11C illustrates a cohesive failure fracture within a tooth in a specimen of the group containing 10 wt.\% zirconia and cracks were visible on the remained layer of the tooth surface at low

Table 3 Mean and Standard Deviation (SD) of Tensile Bond Strength Values (N) with a Count of Teeth Failure Types

\begin{tabular}{|c|c|c|c|}
\hline \multirow[t]{2}{*}{ Experimental Groups } & \multicolumn{3}{|c|}{ Tensile Bonding Strength (N) ( \pm SD) } \\
\hline & Central & Lateral & Canine \\
\hline GI (Control, 0\%) & $645.4(84.8)^{\mathrm{A}}$ & $306.1(81.6)^{\mathrm{A}}$ & $496.7(179.1)^{A}$ \\
\hline G2 (I.5\%) & $534.4(115.3)^{\mathrm{A}}$ & $304.7(86.4)^{\mathrm{A}}$ & $514.0(143.2)^{\mathrm{A}}$ \\
\hline G3 (3\%) & $685.7(159.6)^{\mathrm{A}}$ & $281.1(78.3)^{\mathrm{A}}$ & $462.6(122.1)^{\mathrm{A}}$ \\
\hline G4 (5\%) & $5 \mid 4.5(134.3)^{\mathrm{A}}$ & $229.8(67.3)^{\mathrm{A}}$ & $387.2(99.4)^{A}$ \\
\hline G5 (7\%) & $261.5(66.0)^{\mathrm{B}}$ & $172.5(57.4)^{\mathrm{B}}$ & $271.9(86.3)^{\mathrm{B}}$ \\
\hline G6 (I0\%) & $332.1(122.9)^{B}$ & $165.4(48.7)^{B}$ & $301.6(73.2)^{\mathrm{B}}$ \\
\hline
\end{tabular}

Notes: Within a column, cells having similar (upper case) letters are not significantly different from the control ( $0 \%$ zirconia content) value; $\mathrm{N}=10$ specimens per group. 


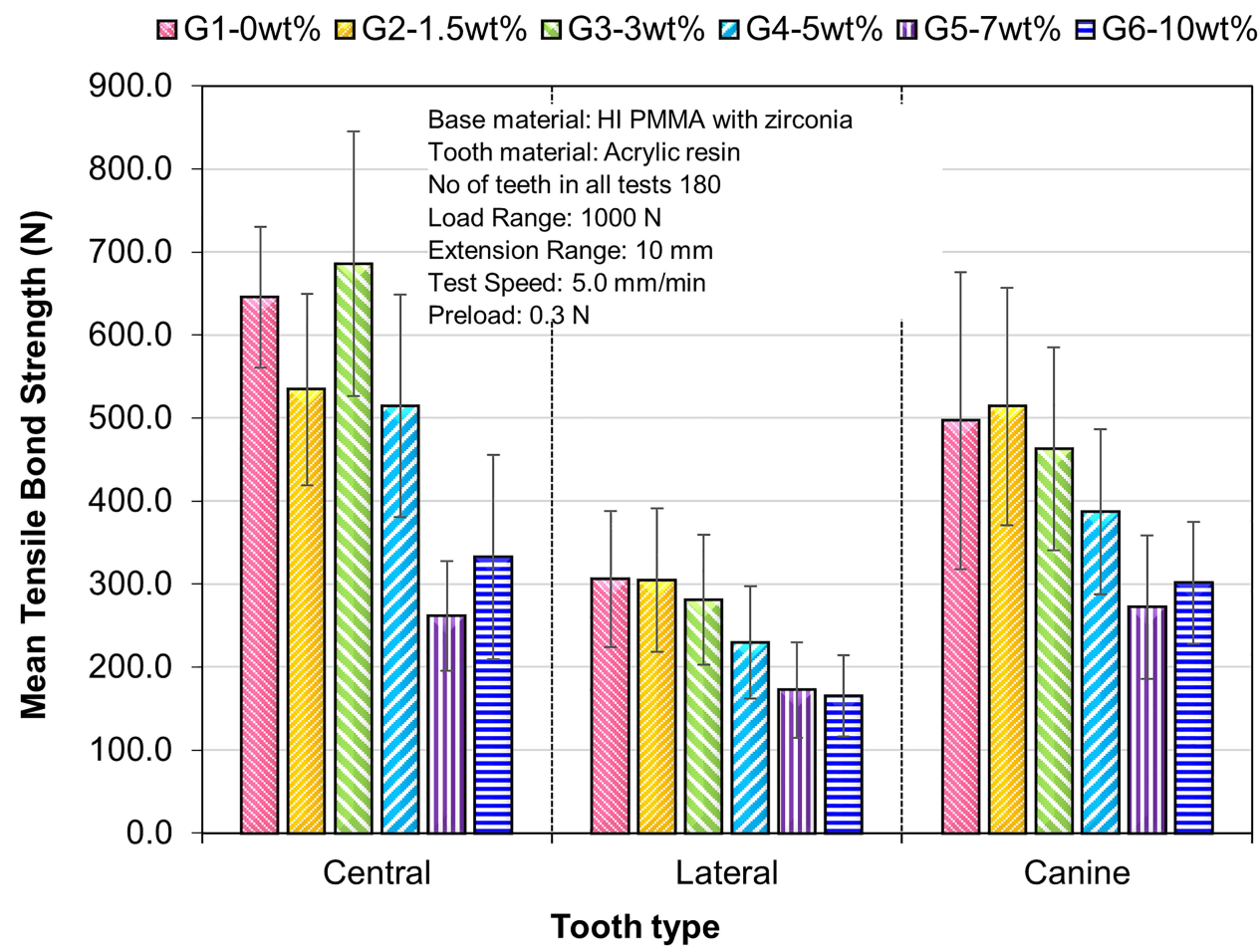

Figure 7 Bar chart showing the mean and standard deviation of TBS values between anterior teeth (central, lateral and canine) and denture base nanocomposites.

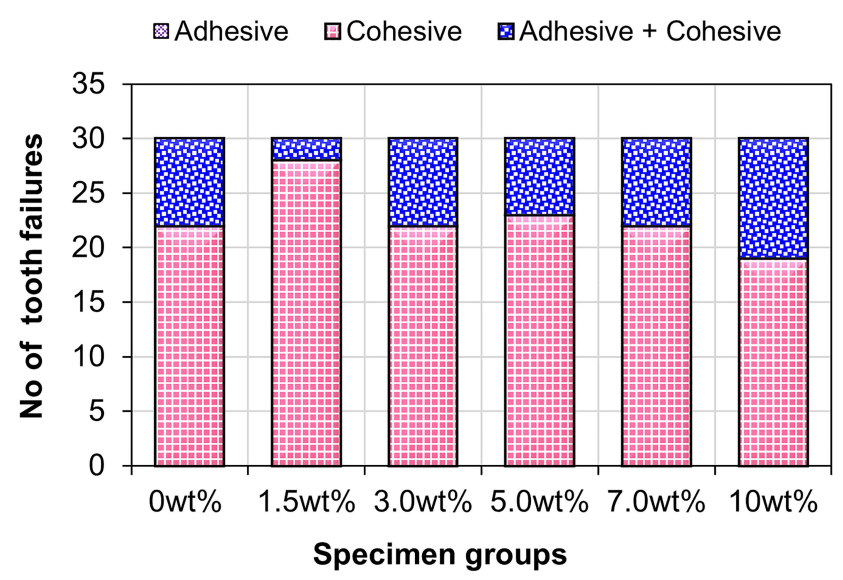

Figure 8 Bar chart showing the modes of tooth failures in the studied groups.

magnification $(50 \times)$. However, at higher magnification, the propagation of cracks and their direction were clearly visible.

\section{Discussion}

Tensile Bond Strength (TBS) of acrylic teeth in denture bases made from HI PMMA with zirconia nanoparticles was evaluated. Mechanical retention techniques such as ridge lap surface preparation and grooves were applied to increase the contact surface area between the tooth and denture base in order to form an effective interlocking system. Following

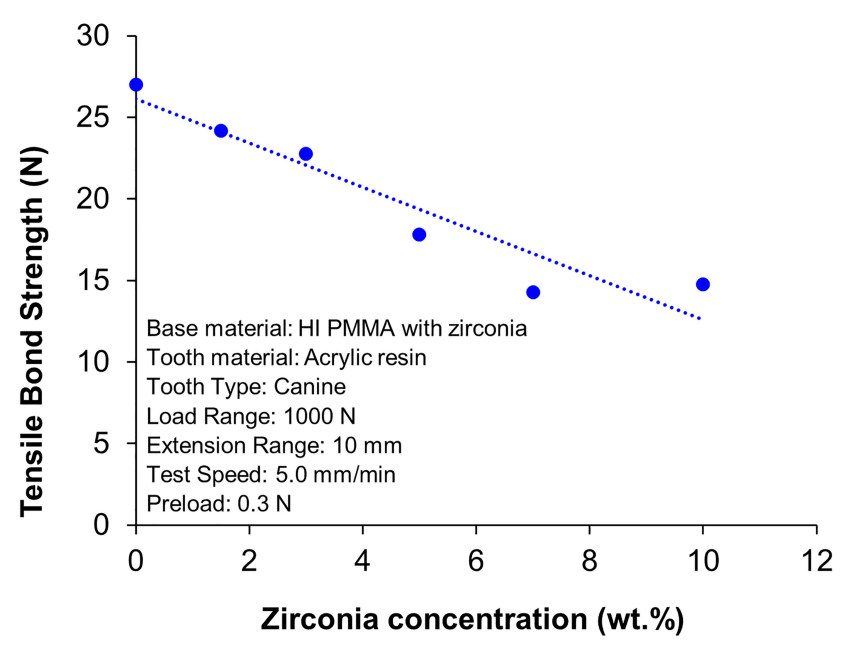

Figure 9 Correlation between zirconia nanoparticle concentrations and tensile bond strength for canine teeth.

these investigations, the original research hypothesis was partially accepted. TBS values of acrylic resin teeth bonded to high-impact PMMA resin reinforced with small concentration of zirconia nanoparticles (1.5 wt.\%, 3 wt. $\%$ and $5 \mathrm{wt}$. $\%)$ showed no significant difference compared to the pure PMMA resin (control group). However, the TBS values for PMMA resin reinforced with higher zirconia concentrations (7 wt.\% and $10 \mathrm{wt} . \%$ ) were significantly lower than those of the control group. With few exceptions, a general trend of 

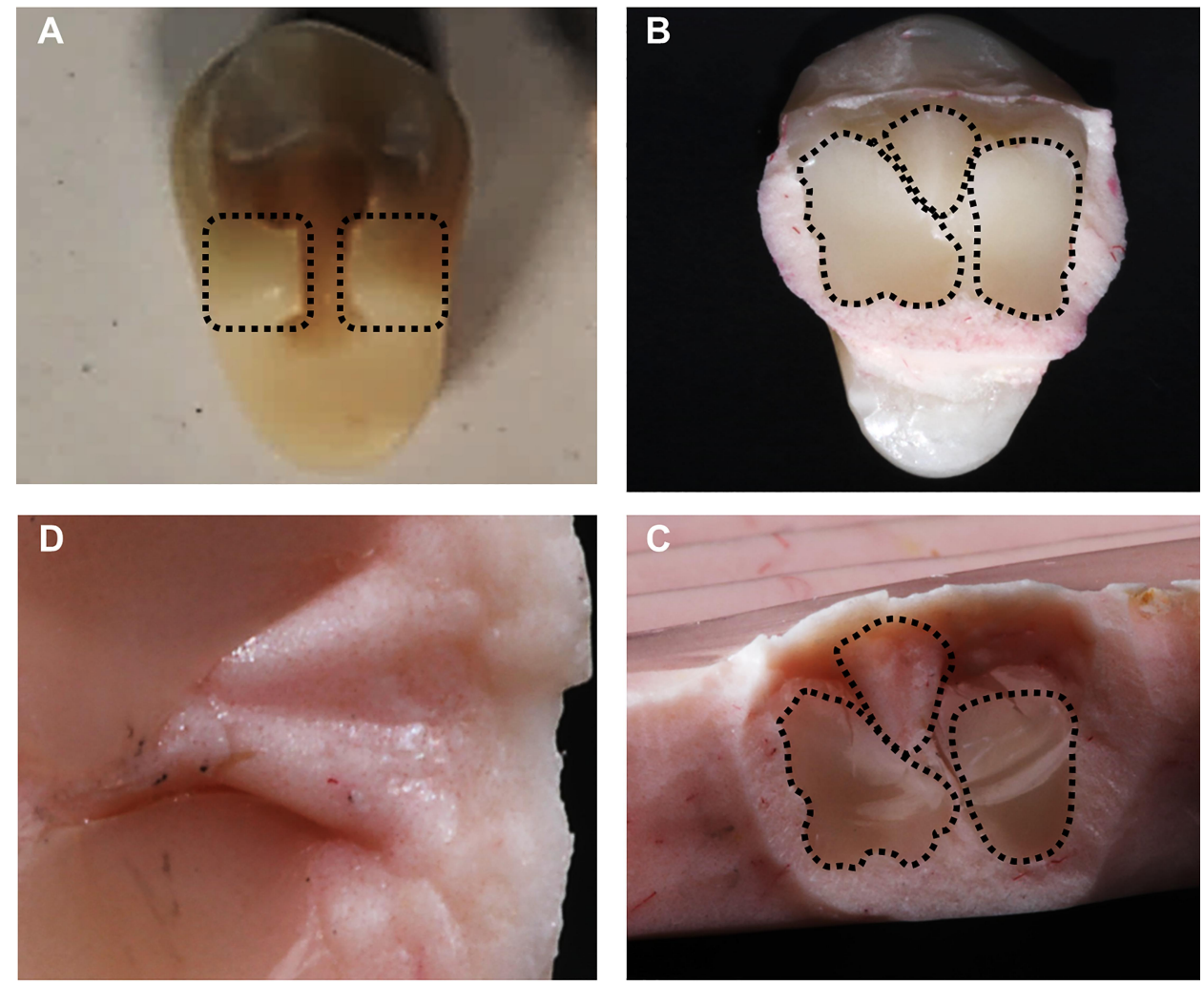

Figure 10 Photographs of $(\mathbf{A})$ canine tooth with groove (dotted boxes highlight the failed area), (B) broken canine tooth from groove root, (C) part of the denture base with broken parts of tooth from the groove (dotted areas in B and C highlight matching broken surfaces in tooth and HI PMMA nanocomposite body) and (D) filling of tooth groove by denture base material.

decreasing bond strength with increasing zirconia concentration was observed for all three tooth types. There was a strong correlation $\left(\mathrm{r}^{2}=0.85\right)$ between zirconia and TBS for canine teeth due to the larger contact surface area present. However, for the central incisor tooth with $3 \mathrm{wt} . \%$ and the canine tooth with $1.5 \mathrm{wt} . \%$ reinforcement, the results demonstrated a higher TBS value when compared to the pure PMMA group. A disruption in the trend was also noticed for the central incisor and canine teeth where the bond strength at $10 \mathrm{wt} . \%$ zirconia was slightly higher than that at 7 wt.\%. In this study, it was clear from the failure behaviour that all the denture base nanocomposites passed the TBS test according to the standard, as there were no pure adhesive failures.

Tensile bond strength values available in literature cannot be directly compared with the reported studies due to the difference in materials or mechanical properties of the artificial denture teeth, denture bases, methods of polymerization used and type of evaluation method applied. ${ }^{2,6}$ In addition, several countries have their own national specification standards. ${ }^{28}$ It is also worth detailing that other studies presented the bond quality in terms of strength
(MPa) calculated by dividing the breaking force with a flat contact area at the interface. Unfortunately, these results cannot be compared as the contact areas were not flat but grooved in this study. ${ }^{7}$ However, the tooth preparation and sample making procedure used in this study were comparable to that used in clinical practice, rather than an "idealised" situation creating a flat surface on the tooth. Only two other studies, which followed a comparable specimen shape and tensile testing procedure, were found in the literature. One study did not report the breaking force during testing as the bond quality was defined by the failure modes only, where 26 tooth debonding occurred through adhesive failures only. ${ }^{29}$ The other study ${ }^{7}$ created a flat surface on the ridge lap area $(5 \mathrm{~mm} \times 5 \mathrm{~mm})$ to measure the bond strength $(17.65 \mathrm{MPa})$ between the acrylic resin polymer tooth and a conventional heat-polymerized PMMA denture base material. The equivalent breaking force (441.25 N) was smaller than the results observed in this study in the groups with lower zirconia concentrations. Furthermore, 57 tooth failures were determined through adhesive modes versus none via this mode for all groups in this study. This demonstrated that HI heat-cured PMMA or zirconia-PMMA 

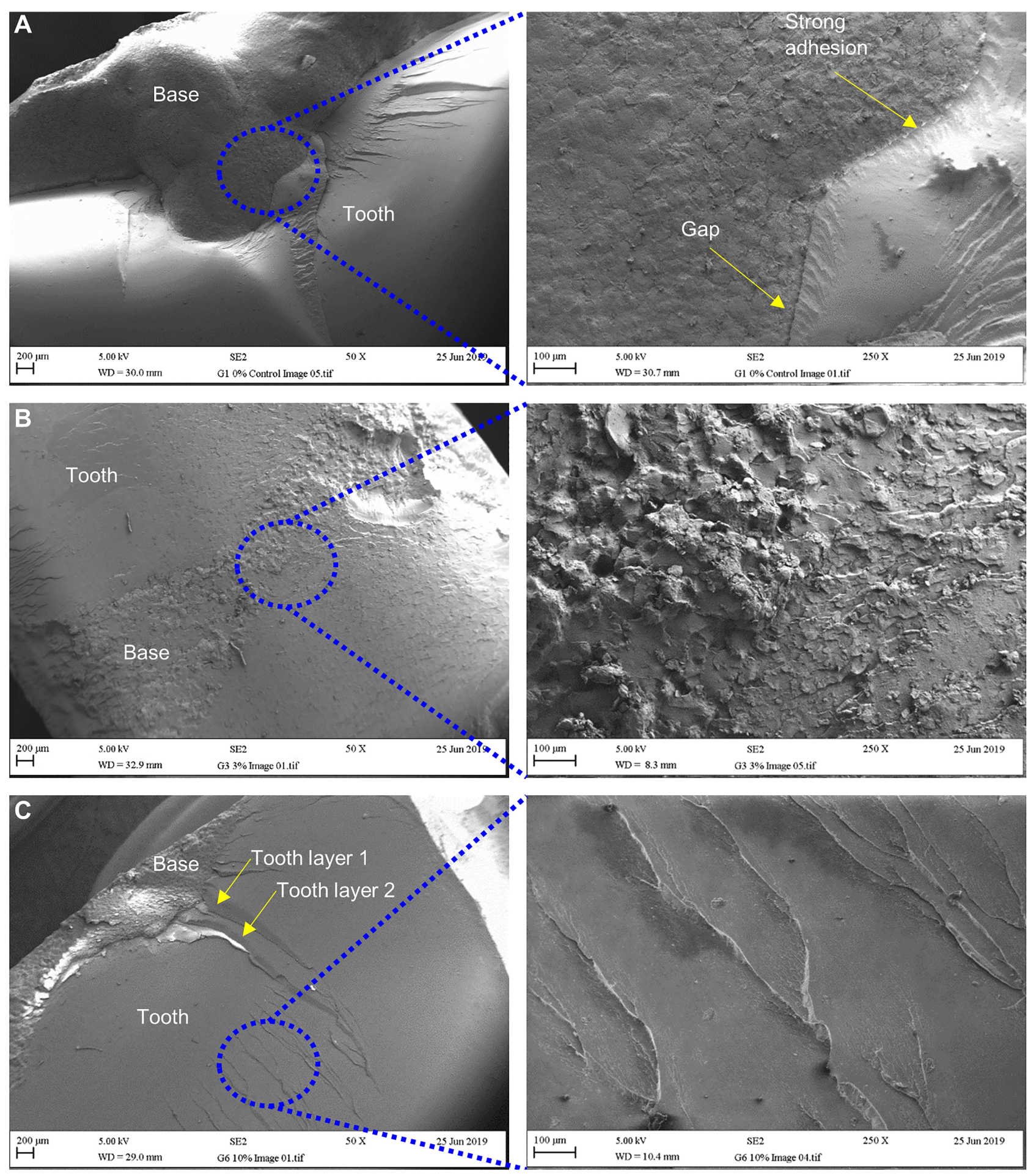

Figure II SEM images of fracture surfaces: (A) mixed cohesive failure with part of denture base material on tooth surface, (B) mixed cohesive failure with layer of denture base material on tooth surface and $(\mathbf{C})$ cohesive failure within tooth showing cracks and their propagation on the fractured tooth surfaces.

nanocomposites could be a better choice to improve the integrity of denture base.

Cardash et al evaluated TBS comparing no retentive features against horizontal and vertical grooves on the ridge lap area with central incisors, lateral incisor and canine teeth bonded to standard and high impact denture base resins. ${ }^{23}$ The findings showed that the highest TBS results were obtained with canines bonded with the aid of vertical retention grooves. An increased surface area on the ridge lap for bonding to acrylic resin, along with the 
vertical groove supporting the mechanical retention of the canine were attributed to this. This was in agreement with the current study, where the improvement in TBS was greater for central incisor and canine teeth rather than the lateral incisor teeth. The lower bonding strengths associated with the lateral incisors could be due to the relatively smaller contact area at the ridge lap, smaller retention grooves, and smaller protruding areas left on both sides of the ridge lap area for effective pulling during tensile testing.

The reason for the apparent reduction in bond strength at higher zirconia concentration is not quite clear. Sprately suggested that during specimen fabrication a rougher surface might trap more wax residue, which could lead to a lower bond strength. With higher zirconia concentrations, surface roughness in the denture base might increase, thus resulting in a decreased bond strength. ${ }^{30}$ In addition, particle clustering found at higher zirconia concentrations, particularly in Group 5 (7 wt \%) and Group 6 (10 wt.\%) could reduce the interaction between the tooth and base materials leading to a weaker bond. ${ }^{25}$ However, the absence of any significant adhesive failure in this study does not fully support this assumption. Studies designed by Suzuki et $\mathrm{al}^{31}$ to evaluate the relationship between adhesive bonding and surface hardness showed that the highly cross-linked resin teeth with higher hardness had poorer bonding to denture base resin compared to normal conventional acrylic teeth having less cross-linking characteristic. In this study, the relative increase in hardness of the denture base with the increase in zirconia concentration $^{25}$ could affect the bond strength. However, this needs further investigation.

According to British Standard (BS EN ISO 22112: 2017) ${ }^{27}$ when the mode of tooth failure occurs cohesively, it means that the bond strength was successfully achieved. In the present study, the vast majority of specimen failures in all the experimental groups occurred in a cohesive manner with the denture teeth leaving a layer of tooth material on the denture base. In contrast, a relatively a small number of teeth (24\%) showed a combination of cohesive and adhesive failure occurred on denture base and/or teeth. These findings are also in agreement with the results presented by other studies. ${ }^{32}$

In this study, a small increase in zirconia concentration led to a reduction in the bond strength. Therefore, the nanocomposite denture base material might play an important role in maintaining the integrity of the denture. Even with optimum zirconia concentration, the denture base nanocomposite did not show any improvement in TBS values over pure PMMA. However, in all cases no adhesive failure or cohesive failure within the denture base was observed. This could indicate that mechanical interlocking and chemical bonding at the interface were strong enough to maintain the integrity of the denture.

From the failure modes, failure statistics and fracture surface characteristics, it was clear that successful bonding was achieved. Therefore, the integrity of the bond was limited by the strength of the tooth rather than the strength at the interface or denture base. ${ }^{22}$ Robison et al also reached the same conclusions, whereby the bond strength was determined by the strength of the denture teeth, which could be affected by the processing technique. ${ }^{32}$ The Artic 6 acrylic teeth used in this study contained multilayer structures. Therefore, during tensile testing, the applied load on the lingual surface near the incisal third of the tooth caused high stress not only at the tooth-denture base bond, but also within the tooth, leading to cohesive failure of the teeth. ${ }^{9}$ Figure $11 \mathrm{C}$ shows the different layers in a fractured tooth surface. Other studies have also shown that newly developed composite/nanocomposite tooth types did not appear to show any improvement over the existing acrylic teeth. However, the addition of monomers to the tooth surface did increase the shear bonding strength. ${ }^{33}$

A study conducted by Clancy et al assessed the TBS on heat-cured and auto polymerization resins with two types of denture teeth (regular acrylic and IPN abrasionresistant). The findings illustrated that the highest TBS was obtained with heat-cured resin bonded to regular acrylic teeth, and they suggested this was because the heatcured resin underwent complete polymerization when compared to the auto polymerization resin. Moreover, the degree of cross-liking also affected the TBS. Furthermore, the regular acrylic teeth having less cross-linking than the abrasion-resistant IPN teeth showed significantly higher bond strength to heat-cured acrylic resin. ${ }^{34}$ It is also expected that the regular teeth and heat-cured PMMA used in this study formed a better chemical compatibility to create a stronger bond.

In this study, a number of good practices were followed during the specimen preparation, which included thoroughly cleaning wax at the ridge lap area, creating retention groove in the teeth, using teeth with cross-linking characteristics, adding MMA monomer (liquid) on the ridge lap surface of the tooth and strictly following the manufacturer's instructions during polymer processing. ${ }^{35}$ 
It was believed that the application of these good practices optimized the processing conditions and made the bond strength as high as possible in order to resist debonding under the application of tensile loading. The absence of a single adhesive failure also indicated that specimen preparation was consistent for all teeth. The findings from this study could influence future clinical practices when preparing denture base materials, thus resulting in reduced numbers of tooth failures, reduced denture repair visits to the clinical provider and increased patient satisfaction.

In the mixed mode failure, small areas of adhesive failure appeared on the incisal side of the tooth where the load was applied. However, the fracture propagated into the denture tooth body and failed cohesively. Cohesive tooth failure in the groove area has been observed in other studies. ${ }^{8,36}$ Therefore, this fracture behaviour indicated that the teeth were more brittle or less strong than the nanocomposite denture bases. Evidence was found that the grooves were filled by the denture base acrylic leading to an increased mechanical retention and improved bond strength by effectively locking the teeth into the denture base. ${ }^{8,23}$ Vallitu ${ }^{36}$ also attributed the stronger bond to penetration of the denture base resins into the grooves, and greater contact surface area.

Another outcome of this study was that a number of shortcomings were identified in the British Standard used to conduct the tests, and the second null hypothesis has been rejected. Firstly, it does not specify any minimum breaking force or strength for assessing an acceptable bond quality, which was only defined by the type of failure. Secondly, the standard does not specify the unit of the bonding strength to be used in terms of maximum breaking forces in $\mathrm{N}$ or stress in $\mathrm{MPa}$, and does not provide any guidance in making the ridge lap surface flat for calculating the bond strength by dividing the contact area with the maximum tensile breaking force. Again, displacing teeth from both sides does not represent the real clinical scenario during mastication as a combination of other types of forces such as shear or bending forces could also be involved. It was found that setting up the pulling head with different tooth types was also very challenging due to its inherently poor design, which could cause inconsistencies in test results. Therefore, a revision of the standard in the light of the above points could be beneficial for reporting test results in a consistent manner.

Variations in TBS values were somewhat higher due to the scattering of results. Previous investigations also reported high variation in the bond strengths. ${ }^{7,35}$ High repeatability of specimen fabrication could be an important factor in obtaining consistent bond strength results. Careful attention was given during denture base, tooth and denture specimen preparation and fabrication. However, any inconsistency in tooth grinding or grooving, positioning of teeth on the denture specimen base in terms of contact surface area at the ridge lap, depth of ridge lap into the base and length of tooth protruding from either side of the base could cause inconsistency in the tests undertaken. Experimental error during tensile testing could also come from minor errors in positioning the teeth with respect to the adjusting screw in the pulling head. This could be due to only a small protruding part of a tooth engaged with the screw in the pulling head. Additionally, one screw was pulling from one side and the other screw was not fully engaged due to minor geometrical inconsistency in the denture specimens or differences in tooth geometry on the two sides of the ridge lap area.

In this study, only mechanical modifications of the tooth surfaces were conducted through grinding and grooving. Further investigations need to be carried out to evaluate the effect of other surface treatments on the tooth ridge-lap such as monomer and adhesive bonding of the teeth with low and high cross-linking characteristics. Moreover, the influence of types of teeth having different mechanical properties (eg, surface hardness) could also be studied to select appropriate teeth for achieving maximum bonding with zirconia impregnated denture base nanocomposites. More recently, it was found that shear bond strength was significantly improved when surface treatments were carried out by laser compared to mechanical and/or chemical surface treatments. ${ }^{37}$ This option could also be explored in future to further improve the bond strength of zirconia-PMMA nanocomposites. Considering the current limitation of the test procedure following the British Standard other testing methods such as micro shear tests could also be explored to obtain more accurate results. ${ }^{38}$ Attempts to improve bond strengths by chemical or mechanical modification of the ridge lap surface of denture teeth have also been investigated. ${ }^{39}$ A combination of mechanical modification by removing ridge lap surface glaze, followed by chemical treatment such as the application of dichloromethane was recommended to achieve the best bonding result.

The major limitation of this work was the in-vitro nature of the bond strength tests, where tooth failure was simulated under idealised static loading conditions, which may not be comparable to "real life" in-vivo conditions where multiple combinations of variable cyclic loading exist. Therefore, extrapolation of the in-vitro bond strength failure results may not be directly applicable under clinical conditions. Another 
limitation of the work was not considering the effect of artificial ageing such as bringing the samples in contact with disinfectants or applying thermal cycling. Studies have shown that bond strength between acrylic teeth and denture base resins could be affected by aging processes such as thermocycling procedure, which could decrease the overall bond strength. ${ }^{40,41}$ Baia et $\mathrm{al}^{42}$ concluded that prolonged bleaching either post- and pre-restoration using 4\% hydrogen peroxide decreased tooth bonding. However, in another study, decreased bond strength was found in teeth bonded to CAD/ CAM and 3D printed denture base resins, when compared to the heat cured acrylic resin, with no significant influence following aging. ${ }^{43}$ Matos et $\mathrm{al}^{5}$ also demonstrated that bond strength between denture teeth and microwave-cured acrylic resin denture base could be reduced when under the influence of disinfectants. Given these outcomes, similar studies could be replicated to understand the effect of artificial aging on the tooth bonding strength with the nanocomposites in this study.

\section{Clinical Implications}

The results obtained from this in-vitro investigation suggest that the tensile bond strength between high-impact heat-cured PMMA denture base impregnated with small quantities of zirconia nanoparticles and acrylic teeth were equally good when compared to the same with pure PMMA, while also providing improved mechanical properties than the latter. An appropriate concentration of zirconia (between 1.5 wt.\% to 5 wt.\%) should be considered to maximize the bond strength in clinical practice.

\section{Conclusion}

Within the experimental limitations of this in-vitro study, the following conclusions can be drawn.

The tensile bond strength (TBS) between tooth and HI PMMA denture base nanocomposites with $1.5 \mathrm{wt} \% \%$, 3 wt. $\%$ and $5 \mathrm{wt} . \%$ of $\mathrm{ZrO}_{2}$ was not significantly different than the control group (without zirconia). However, the nanocomposites with 7 wt.\% and 10 wt.\% zirconia displayed relatively poorer strength compared to the control group. Among the denture base nanocomposites, $3 \mathrm{wt} \%$ zirconia impregnated PMMA could be the optimum denture base material for obtaining highest bonding strength, which could be comparable to pure PMMA resin.

The most common mode identified was cohesive failure through fracture within the teeth. A few mixed modes in combination with cohesive and adhesive failures were also observed but no pure adhesive failure at the interface between the teeth and denture base, an indicator of poor bonding, was recorded. The results also suggested that the tooth failure in denture was not limited by the bond strength or strength of denture bases rather the strength of the teeth.

\section{Abbreviations}

PMMA, polymethyl methacrylate; MMA, methyl methacrylate; HI, high-impact; TBS, tensile bond strength; SD, standard deviation; SEM, scanning electron microscope.

\section{Acknowledgments}

The authors would like to thank the ministry of higher education of Libya for providing financial support for $\mathrm{PhD}$ study; David Watts and Brian Daber from Department of Dental Biomaterial, University of Manchester; Paul Murphy from University Dental Hospital of Manchester; Michael Green and Hayley Andrews from the Faculty of Science and Engineering, Manchester Metropolitan University and Gary Pickles from School of Materials, University of Manchester, for supporting the experimental work.

\section{Author Contributions}

All authors contributed to data analysis, drafting or revising the article, have agreed on the journal to which the article will be submitted, gave final approval of the version to be published, and agree to be accountable for all aspects of the work.

\section{Funding}

This research received no external funding.

\section{Disclosure}

The authors report no conflicts of interest in this work.

\section{References}

1. Saavedra G, Valandro LF, Leite FPP, et al. Bond strength of acrylic teeth to denture base resin after various surface conditioning methods before and after thermocycling. Int $J$ Prosthodont. 2007;20 (2):199-201.

2. Chaves C, Regis RR, Machado AL, et al. Effect of ridge lap surface treatment and thermocycling on microtensile bond strength of acrylic teeth to denture base resins. Braz Dent J. 2009;20(2):127-131. doi:10.1590/S0103-64402009000200007

3. Moffitt AR, Woody RD, Parel SM, et al. Failure modes with point loading of three commercially available denture teeth. J Prosthodont. 2008;17(6):432-438. doi:10.1111/j.1532-849X.2008.00320.x

4. Clements JL, Tantbirojn D, Versluis A, et al. Do denture processing techniques affect the mechanical properties of denture teeth? J Prosthet Dent. 2018;120(2):246-251. doi:10.1016/j.prosdent.2017.10.025

5. Matos AO, Costa JO, Beline T, et al. Effect of disinfection on the bond strength between denture teeth and microwave-cured acrylic resin denture base. J Prosthodont. 2018;27(2):169-176. doi:10.1111/ jopr.12468 
6. Palitsch A, Hannig M, Ferger P, et al. Bonding of acrylic denture teeth to MMA/PMMA and light-curing denture base materials: the role of conditioning liquids. J Dent. 2012;40(3):210-221. doi:10. 1016/j.jdent.2011.12.010

7. Kurt M, Saraç YŞ, Ural Ç, Saraç DJG. Effect of pre-processing methods on bond strength between acrylic resin teeth and acrylic denture base resin. Gerodontology. 2012;29(2):e357-e62. doi:10. 1111/j.1741-2358.2011.00480.x

8. Patil SB, Naveen BH, Patil NP. Bonding acrylic teeth to acrylic resin denture bases: a review. Gerodontology. 2006;23(3):131-139. doi:10. $1111 / \mathrm{j} .1741-2358.2006 .00129 . x$

9. Cunningham JL. Bond strength of denture teeth to acrylic bases. J Dent. 1993;21(5):274-280. doi:10.1016/0300-5712(93)90106-Z

10. Colebeck AC, Monaco EA, Pusateri CR, et al. Microtensile bond strength of different acrylic teeth to high-impact denture base resins. J Prosthodont. 2015;24(1):43-51. doi:10.1111/jopr.12196

11. Perea L, Matinlinna JP, Tolvanen M, et al. Monomer priming of denture teeth and its effects on the bond strength of composite resin. J Prosthet Dent. 2014;112(2):257-266. doi:10.1016/j.prosdent.2014.02.019

12. Stoia AE, Sinescu C, Negrutiu M, et al. Tensile bond strength of acrylic resin teeth to denture base repair resin. J Adv Comm Comp Sys Circ Dev. 2010;32:337-341.

13. Barpal D, Curtis DA, Finzen F, et al. Failure load of acrylic resin denture teeth bonded to high impact acrylic resins. J Prosthet Dent. 1998;80(6):666-671. doi:10.1016/S0022-3913(98)70053-8

14. Taczała J, Sawicki J. Bond between single artificial teeth and the base plate in removable denture metal framework. J Achiev Mater Manuf Eng. 2018;1:11-21.

15. Tukmachi MS, Azeez ZA, Mohammed DH. Evaluation of bond strength of acrylic artificial teeth with unreinforced and nano silica reinforced denture base material after chemical disinfection. $J$ Res Med Dent Sci. 2018;6(5):76-82.

16. Cardash HS, Liberman R, Helft M. The effect of retention grooves in acrylic resin teeth on tooth denture-base bond. J Prosthet Dent. 1986;55(4):526-528. doi:10.1016/0022-3913(86)90192-7

17. Cunningham J, Benington I. An investigation of the variables which may affect the bond between plastic teeth and denture base resin. J Dent. 1999;27(2):129-135. doi:10.1016/S03005712(98)00034-7

18. Thongrakard T, Wiwatwarrapan C. Tensile bond strength between auto-polymerized acrylic resin and acrylic denture teeth treated with MF-MA solution. J Adv Prosthodont. 2016;8(4):285-289. doi:10. 4047/jap.2016.8.4.285

19. Çulhaoğlu AK, Özkır SE, Şahin V, Yılmaz B, Kılıçarslan MA. Effect of various treatment modalities on surface characteristics and shear bond strengths of polyetheretherketone -based core materials. J Prosthodont. 2020;29(2):136-141. doi:10.1111/jopr.12702

20. Malkoç MA, Demir N, Ögreten AT, Ozturk AN, Kiliç HS. Effect of new laser type on shear bond strength of acrylic teeth to denture base. $J$ Restor Dent. 2015;3(1):26. doi:10.4103/2321-4619.150028

21. Schneider RL, Curtis ER, Clancy JMS. Tensile bond strength of acrylic resin denture teeth to a microwave- or heat-processed denture base. J Prosthet Dent. 2002;88(2):145-150. doi:10.1067/mpr.2002. 127898

22. Andrade de Freitas SL, Brandt WC, Miranda ME, Vitti RP. Effect of thermocycling, teeth, and polymerization methods on bond strength teeth-denture base. Int J Dent. 2374327;2018.

23. Cardash HS, Applebaum B, Baharav H, et al. Effect of retention grooves on tooth-denture base bond. J Prosthet Dent. 1990;64 (4):492-496. doi:10.1016/0022-3913(90)90051-D

24. Gad MM, Abualsaud R, Rahoma A, et al. Effect of zirconium oxide nanoparticles addition on the optical and tensile properties of polymethyl methacrylate denture base material. Int $J$ Nanomed. 2018;13:283-292. doi:10.2147/IJN.S152571
25. Zidan S, Silikas N, Alhotan A, et al. Investigating the mechanical properties of $\mathrm{ZrO}_{2}$-impregnated PMMA nanocomposite for denture-based applications. Materials (Basel). 2019;12(8):1344. doi: $10.3390 / \mathrm{ma1} 2081344$

26. Zidan S, Silikas N, Haider J, Yates J. Effect of cleansers on the colour stability of zirconia impregnated PMMA bio-nanocomposite. Nanomaterials. 2020;10(9):1757. doi:10.3390/nano10091757

27. (BSI) BSI. Dentistry-Artificial Teeth for Dental Prostheses. London: BSI Standards Limited; 2017.

28. Clark WA, Hsu YT. The effect of autopolymerizing acrylic resin thickness on the bond strength of a repaired denture tooth. J Prosthodont. 2014;23(7):528-533. doi:10.1111/jopr.12156

29. Korkmaz T, Dogan A, Murat Dogan O, et al. The bond strength of a highly cross-linked denture tooth to denture base polymers: a comparative study. J Adhes Dent. 2010;13(1):85.

30. Spratley MH. An investigation of the adhesion of acrylic resin teeth to dentures. J Prosthet Dent. 1987;58(3):389-392. doi:10.1016/00223913(87)90065-5

31. Suzuki S, Sakoh M, Shiba A. Adhesive bonding of denture base resins to plastic denture teeth. J Biomed Mater Res. 1990;24 (8):1091-1093. doi:10.1002/jbm.820240811

32. Robison NE, Tantbirojn D, Versluis A, et al. Failure strengths of denture teeth fabricated on injection molded or compression molded denture base resins. J Prosthet Dent. 2016;116(2):292-299. doi:10. 1016/j.prosdent.2016.02.001

33. Ghaffari GT, Hamedirad F, Miruzadeh K. Comparison of bond strength of acrylic, composite, and nanocomposite artificial teeth to heat-cure acrylic denture base resin. Front Dent. 2019;16(3):166-172.

34. Clancy JMS, Boyer DB. Comparative bond strengths of light-cured, heat-cured, and autopolymerizing denture resins to denture teeth. $J$ Prosthet Dent. 1989;61(4):457-462. doi:10.1016/0022-3913(89) 90014-0

35. Radford DR, Juszczyk AS, Clark RKF. The bond between acrylic resin denture teeth and the denture base: recommendations for best practice. Br Dent J. 2014;216(4):165-167. doi:10.1038/sj.bdj.2014.99

36. Vallittu PK. Bonding of resin teeth to the polymethyl methacrylate denture base material. J Acta Odontol Scand. 1995;53(2):99-104. doi:10.3109/00016359509005954

37. Akin H, Kirmali O, Tugut F, Coskun ME. Effects of different surface treatments on the bond strength of acrylic denture teeth to polymethylmethacrylate denture base material. Photomed Laser Surg. 2014;32(9):512-516. doi:10.1089/pho.2014.3732

38. Andrade AM, Garcia E, Moura SK, et al. Do the microshear test variables affect the bond strength values? Int $J$ Dent. 2012;2012:618960. doi:10.1155/2012/618960

39. Sharma E, Kumar M, Sharma R, Bansal A, Katoch S. Comparative evaluation of bond strength between ridge lap surface of acrylic teeth and denture base resin: an in vitro study. Dent J Adv Stud. 2019;7 (01):012-018. doi:10.1055/s-0039-1684881

40. Aguiar EF, Tonani R, de Goes Paiola F, et al. Influence of aging on bond strength of artificial teeth to denture base acrylic resins. Braz J Oral Sci. 2018;17:e18373-e18373. doi:10.20396/bjos.v17i0.8652929

41. Abd El Hameed HM. An-invitro comparison of thermocycling effect on micro-hardness and micro-tensile bond strength of nano composite denture teeth. Egypt Dent J. 2019;65(2):1495-1501. doi:10.21608/ edj.2019.72574

42. Juliana CP, Baia RP, Oliveira MES, et al. Influence of prolonged dental bleaching on the adhesive bond strength to enamel surfaces. Int J Dent. 2020;2609359.

43. Choi JJE, Uy CE, Plaksina P, Ramani RS, Ganjigatti R, Waddell JN. Bond strength of denture teeth to heat-cured, CAD/CAM and 3D printed denture acrylics. J Prosthodont. 2020;29(5):415-421. doi:10.1111/jopr.13125 


\section{Publish your work in this journal}

The International Journal of Nanomedicine is an international, peerreviewed journal focusing on the application of nanotechnology in diagnostics, therapeutics, and drug delivery systems throughout the biomedical field. This journal is indexed on PubMed Central, MedLine, CAS, SciSearch ${ }^{\mathbb{R}}$, Current Contents ${ }^{\mathbb{B}} /$ Clinical Medicine,
Journal Citation Reports/Science Edition, EMBase, Scopus and the Elsevier Bibliographic databases. The manuscript management system is completely online and includes a very quick and fair peer-review system, which is all easy to use. Visit http://www.dovepress.com/ testimonials.php to read real quotes from published authors.

Submit your manuscript here: https://www.dovepress.com/international-journal-of-nanomedicine-journal 